\title{
Para un estudio de la recepción de la obra de Antonio Tabucchi en España
}

\author{
AssumPta CAMPS
}

Universidad de Barcelona

Antonio Tabucchi (Vecciano, 1948) es, sin duda, el escritor italiano de su generación que goza de una mayor proyección internacional con éxitos tan importantes como la reciente novela Sostiene Pereira (1994), que culmina una carrera literaria iniciada en los años 70 y que cuenta ya con una veintena de obras.

En este artículo estudiaremos la recepción de su obra en el ámbito hispano, con particular atención a las divergencias que se observan en la traducción de su producción literaria en catalán y castellano, y que obedecen a las particularidades propias de cada sistema literario.

\section{INMEDIATEZ DE TABUCCHI EN TRADUCCIÓN CASTELLANA}

Tabucchi empieza a ser traducido y publicado en España a mediados de la década de los 80, siendo su primera obra conocida en esta lengua Donna di Porto Prim (1983), que presenta la editorial Anagrama poco después de su aparición en Italia, es decir, en 1984. A partir de ese momento, se irán sucediendo, con una celeridad inusitada en el panorama de la recepción de la literatura italiana entre nosotros, las traducciones de obras suyas, con tan sólo uno o dos años de distancia de la primeras ediciones italianas. Este es el caso de Notturno indiano (1984 en Italia, 1985 en España), Piccoli equivoci senza importanza (1985, frente a 1987 en España), Il filo dell'orizzonte (1986, frente a 1988), L'angelo nero (1991, frente a 1993), Sostiene Pereira (1994, frente a 1995). Esta tendencia se acentúa, hasta alcanzar la estricta contemporaneidad, con La testa perduta di Damasceno Monteiro (publicada el mismo 1997 en uno y otro país). Habrá, sin embargo, algunas excepciones a esta tónica general en la 
recepción española de su obra, pero hablamos en todos los casos de desfases temporales de cinco o seis años como mucho, algo insignificante si lo comparamos con otros escritores italianos de este mismo siglo. Sc trata, por ejemplo, de $I /$ gioco del rovescio (1981 frente a 1986) o Requiem (publicada en portugués en 1986) que no se dará a conocer en España hasta 1994.

De hecho, dentro de esta tendencia, el éxito de Sostiene Pereira no sólo determinó una mayor celeridad de recepción -cómo se observa, por ejemplo. en la inmediatez con que se presenta al público español La testa perduta di Damasceno Monteiro (1997)- y por tanto un menor desfase temporal entre primeras ediciones, italiana y española, sino también la recuperación de buena parte de su obra anterior como Sogni di sogni (de 1992, presentado en España en 1996), o el mismo Requiem, anteriormente citado, así como la reedición de sus obras traducidas anteriormente en España, si bien es cierto que este proceso de recuperación se había iniciado ya unos años antes, gracias a la buena acogida de Notturno indiano. Así, por ejemplo, veremos traducido /l gioco del rovescio en 1986, como ya apuntábamos arriba. Sin embargo, sus obras aparecidas en los 70 quedarán claramente postergadas, y aún hoy siguen sin estar traducidas entre nosotros. Nos referimos a Piazza d'Italia (1975) y a I/ piccolo naviglio (1978), sin duda títulos menores de su producción, pero que a pesar de ello merecerían quizá un poco más de atención. En el mismo sentido, hay que hablar de otro título bastante más reciente, y sin embargo desconocido, como es Dialoghi Mancanti (1988).

Como vemos, a pesar de estas escasas excepciones, las traducciones y reediciones de sus obras muestran una buena dinámica, y una periodicidad de uno o dos años, gracias a la labor de la editorial Anagrama, fundamentalmente. No podemos decir lo mismo, sin embargo, de su recepción catalana, como tendremos ocasión de analizar más tarde. La recepción de Tabucchi en ámbito hispano se localiza casi exclusivamente en Barcelona, y desde un primer momento, aunque con más razón en la actualidad dada la exclusividad de derechos de traducción que ostentan Anagrama, para el castellano, y Edicions 62 para el catalán. Cabe citar la excepción de Un baúl lleno de gente. que verá la luz gracias a la editorial Huerga y Fierro de Madrid, aunque con licencia de Anagrama, sin duda por el carácter de estudio de la obra de Fernando Pessoa que reviste esta obrita no carente de interés literario, por cierto.

El título de Tabucchi que arroja un mayor número de ediciones en España es sin lugar a dudas Sostiene Pereira, novela que cuenta ya con más de 15 ediciones en castellano, básicamente por Anagrama (aunque hay que añadir a ellas las del Círculo de Lectores y de RBA Editores), constituyendo un verdadero boom editorial, verdaderamente insólito, como decíamos, en la historia de la recepción de Ja literatura italiana contemporánea. Hasta 1995, sus traducciones acostumbran a reeditarse dos o tres veces, a lo sumo cinco, con Notturno indiano. Pero los años 1996 y 1997 marcan un cambjo radical en este panorama, siendo así que además de las primeras ediciones castellanas 
de Sogni di sogni (1996), La testa perduta di Damasceno Monteiro (1997) o Un baule pieno di gente (1997), a las que cabe añadir, en los dos primeros casos, traducciones paralelas al catalán de los mismos años, hay que hablar de múltiples reediciones de sus obras anteriores. Así, por ejemplo: Donna di Porto Pim (1996 en castellano), Notturno indiano (1995 en castellano, 1997 en catalán y castellano), $I l$ gioco del rovescio (1997 en castellano), Piccoli equivoci senza importanza (1997 en castellano), Il filo dell' orizzonte (1997 en castellano), Il volatili del Beato Angelico (1997 en castellano), L'angelo nero (1997 en castellano) o Requiem (1996 y 1997 en castellano). Como consecuencia de este boom editorial, el lector tiene a su disposición en nuestras librerías un total de siete obras de Tabucchi en 1996 y nueve en 1997, lo cual no deja de ser sorprendente.

Sin lugar a dudas una de las claves de este éxito se debe al estreno de la película "Sostiene Pereira", basada en su novela homónima. Y ciertamente el éxito de la película ha contribuido notablemente a hacer que Tabucchi fuera conocido por el gran público, cumpliéndose una vez más la norma según la cual la película juega un papel importante en la promoción de un libro, hecho que se ha sabido aprovechar fehacientemente en las editoriales que cuentan en la actualidad con los derechos de traducción en exclusiva, es decir Anagrama y Edicions 62.

\section{TABUCCHI EN CATALÁN}

La traducción de la obra de Tabucchi al catalán es, en líneas generales, subsidiaria de su introducción en España por Anagrama, aunque la primera muestra, Petits equívocs sense importància, publicada en Barcelona en 1986, curiosamente no verá la luz en castellano hasta un año más tarde. La Editorial Pòrtic es responsable de esta primera atención por Tabucchi que comprende la obra citada, seguida de El fil de l'horitzó, publicada el año siguiente (1987), ambas inmediatamente después de las primeras ediciones italianas de 1985 y 1986 respectivamente. Por tanto, aunque la recepción catalana no precede, en términos absolutos, a la castellana (a diferencia de lo que ocurre en la recepción de muchos autores italianos de este siglo), sin embargo se anticipa en lo que a estas dos obras coetáneas, publicadas por la Editorial Feltrinelli de Milán, se refiere. Las obras anteriores de Tabucchi, en especial títulos de innegable relieve como Donna di Porto Pim (1983) o, sobre todo, Notturno italiano (1984), ambos publicados por Sellerio de Palermo, se verán dejados de lado en ámbito catalán por un tiempo, por no hablar de otros títulos menores de su producción. Siendo así que la traducción de sus obras o alcanza cierta regularidad en catalán hasta bien entrada la década de los años 90 . Y esta, o sólo es muy reciente, como veremos, sino que, como viene siendo habitual en el contexto editorial catalán, también es muy reducida y parcial. 
De hecho, se limita a tan sólo 7 títulos, entre los cuales, además de los dos ya citados, que no conocen ninguna reedición, cabe citar Nocturn a l'India, presentado por primera vez en esta lengua por la Editorial Bromera de Alzira, en la tardía fecha de 1992 ( 8 años más tarde de su presentación en Italia, y 7 años después de la traducción de anagrama, reeditada mientras tanto en dos ocasiones más, en 1987 y 1988!); Afirma Pereira, publicado por Edicions 62 de Barcelona en 1995; Somni di somnis. Els tres últims dies de Fernando Pessoa (1996) y El cap perdut de Damasceno Monteiro (1997), ambas por Edicions 62. Sin duda la discontinuidad editorial que observamos ha afectado a la traducción al catalán de la obra de Tabucchi, que parece regularizarse, sin embargo, a partir del éxito intemacional de Sostiene Pereira, y del momento en que Edicions 62 se hace cargo de ella de forma exclusiva. Hasta tal punto esta es así que no sólo hallamos, a partir de entonces, una traducción de Tabucchi cada año, prácticamente al ritmo de aparición que hemos constatado para el castellano, sino que observamos, además, que se reedita la traducción anterior de Nocturn a l'índia en 1993 y 1997, colocando esta obra en el lugar que se merece en el panorama de la narración contemporánea, después de años de inexplicable desatención en ámbito catalán. Ni qué decir tiene que, una vez más, la popularidad adquirida por el autor a partir de 1995 ha contribuido notablemente a su éxito editorial también en este reducido mercado. Quedan, sin embargo, muchas obras del autor por dar a conocer al público catalán, y esperamos que el éxito reciente sirva, no tan sólo para acelerar su recepción a partir de ahora, sino para recuperar parte de su producción anterior que ha quedado en el olvido.

\section{LOS TRADUCTORES DE TABUCCHI}

Capítulo aparte, pero no exento de interés, es el que hace referencia a los traductores de Tabucchi en España. La primera traductora de su obra fue Carmen Artal, conocida por sus versiones de Bruno Munari, de Melandri o de Andrea de Carlo, así como de Baudelaire entre otros. A ella se deben Dama de Porto Pim, Nocturno hindú y El juego del revés. Joaquim Jordá, conocido como traductor de Leonardo Sciascia o Giorgio Manganelli, además de por sus versiones de $\mathrm{M}$. Foucault, o de Rousseau, y traductor, a su vez, de autores catalanes al castellano (entre los que cabe citar a Quim Monzó, Ferran Torrent o Pere Calders), substituyó a C. Artal en Anagrama para Pequeños equívocos sin importancia y La línea del horizonte entre 1987 y 1988. Sin embargo, los mayores traductores de Tabucchi al castellano son Javier González Rovira y Carlos Gumpert, que ha traducido conjuntamente toda su producción restante (excepto Un baúl lleno de gente, obra de Pedro Luis Ladrón de Guevara), y se han especializado en Tabucchi desde 1991, siendo por su parte, Gumpert el traductor habitual de Tabucchi para la prensa periódica española. Anagrama ha presentado casi exclusivamente su obra 
a esta lengua, haciéndose cargo de los derechos de traducción (que ha cedido tan sólo para Un baul lleno de gente, ensayo literario sobre la obra de Pessoa, como decíamos) desde hace años, con singular perspicacia, y buena fortuna desde que ha sobrevenido el boom editorial de Tabucchi a mediados de $\operatorname{los} 90$.

En catalán, sin embargo, la discontinuidad observada en las editoriales se repite en lo referente a los traductores, y ni siquiera la exclusividad de derechos que ostenta Edicions 62 ha propiciado una continuidad en este sentido, Las primeras traducciones, presentadas por Pòrtic, son obras de Salvador y Marta Albertí, dos traductores más conocidos por su dedicación a trabajos de lingüística y diccionarios de catalán. El valenciano Joan Francesc Mira, conocido como estudioso de la obra de J. Fuster, además de por sus colaboraciones en prensa (en el semanario nacionalista "El Temps", concretamente), es el responsable de la versión catalana de Nocturn a l'India. por su parte, Xavier Riu, profesor de Filología Clásica y traductor habitual de Edicions 62 es el encargado de la traducción catalana de la muy exitosa Afrima Perira, mientras que Somni de somnis... es obra de otro traductor habitual de la casa y editor, Jordi Cornudella, conocido por dar a conocer a Roberto Pazzi, además de por sus estudios de la obra de J. Carner. Y por último, Pep Julià, traductor del inglés de Allan Brown o Gerald Durrell, entre otros). Son, como vemos, traductores profesionales en su mayoría (excepto en los primeros casos), pero ninguno muestra, desgraciadamente, la especialización y el conocimiento del universo tabucchiano que se advierte en el terreno de la traducción al castellano. Sin embargo, resulta obvio que a partir de la mitad de los 80 en castellano y de los 90 en catalán, la producción de Tabucchi es presentada al público por parte de traductores de renombre en sus respectivos campos, lo cual es índice del prestigio adquirido por el autor, y a la vez, como pez que se muerde la cola, una de las causas que ha contribuido a dignificar la calidad de las traducciones. La reciente profesionalización de la traducción, quizá determina, no obstante, que no hallemos escritores entre las filas de los traductores de la obra de Tabucchi, a diferencia de lo que venía siendo habitual en otras épocas. Con la excepción de Joan Francesc Mira, traductor, como hemos dicho, de Nocturn a l'Índia en catalán.

Sin duda Tabucchi, no siendo un escritor de masas, sino un autor cuya calidad literaria y constantes referencias histórico-literarias lo alejan de la producción literaria de consumo, ha conseguido llegar al gran público. Su reconocimiento es, de hecho, previo al boom editorial, acaecido a mediados de los 90 , dado que ganó numerosos premios literarios con anterioridad, desde el "Medici Étranger" de 1987. El año 1994 es el de su verdadera consagración como escritor en Italia, al ganar Sostiene Pereira el premio Campiello, el ViareggioRapaci o el Premío Scanno. Pero lo cierto es que su traducción a 16 idiomas se debe principalmente al exito de la película homónima. Habrá que ver, pues, a partir de ahora, cuál será su evolución en el futuro, y cómo se comporta la recepción de su obra en ámbito hispano. 


\section{REFERENCIAS BIBLIOGRÁFICAS}

Dama de Porto Pim. trad. de Carmen Artal, Ed. Anagrama, Barcelona, 1984

Reeditada en 1987 y 1996.

Nocturno hindü, trad. de Carmen Artal, Ed. Anagrama, Barcelona, 1985

Reeditada en 1987, 1988, 1995 y 1997.

El juego del revés, trad. de Carmen Artal, Ed. Anagrama, Barcelona, 1986

Reeditada en 1987 y 1997.

Petits equívocs sense importància, trad. de S. y M. Albertí, Ed. Pòrtic, Barcelona, 1986

Pequeños equívocos sin importancia, trad. de J. Jordà, Ed. Anagrama, Barcelona, 1987

Reeditada en 1997.

El fil de l' horitzó, trad. de S. y M. Albertí, Ed. Pòrtic, Barcelona 1987.

La linea del horizonte, trad. de J. Jorda, Ed. Anagrama, Barcelona, 1988

Reeditada en 1997.

Los volatiles del Beato Angélico, trad. de J. González Rovira y C. Gumpert, Ed. Anagrama, Barcelona, 1991

Reeditada en 1997.

Nocturn a l'índia, trad. de J.F. Mira, Ed. Bromera, Alzira, 1992

Reeditada en 1993 y 1997.

El angel negro, trad. de J. Gonzálex Rovira y C. Gumpert, Ed. Anagrama, Barcelona, 1993

Reeditada en 1997.

Requiem, trad. de J. González Rovira y C. Gumpert, Ed. Anagrama, Barcelona, 1995 Reeditada en 1996 y 1997.

Sostiene Pereira, trad. de J. González Rovira y C. Gumpert, Ed. Anagrama, Barcelona, 1995

Reeditada en 1996 y 1997.

Afirma Pereira, trad. de X. Riu, Ed. 62, Barcelona 1995

Sueño de sueños. Los tres últimos días de Fernando Pessoa trad. de J. González Rovi-

ra y C. Gumpert, Ed. Anagrama, Barcelona, 1996

Somni de somnis. Els tres últims dies de Fernando Pessoa, trad. de J. Cornudella, Ed. 62, Barcelona, 1996

Un baúl lleno de gente, trad. de P.L. Ladrón de Guevara, Ed. Huerga y Fierro, Madrid, 1997

La cabeza perdida de Damasceno Monteiro, trad. de J. González Rovira y C. Gumpert, Ed. Anagrama, Barcelona, 1997

El cap perdut de Damasceno Monteiro, trad. de P. Julià, Ed. 62, Barcelona, 1997. 